\title{
Transportation and localization of phenanthrene and its interaction with different species of arsenic in Pteris vittata $\mathrm{L}$.
}

\author{
Xiaoyong Liao*, Xu Ma, Xiulan Yan, Longyong Lin, Peili Shi, Zeying Wu \\ Beijing Key Laboratory of Environmental Damage Assessment and Remediation, Institute of Geographical Sciences and Natural Resources Research, Chinese
} Academy of Sciences (CAS), Beijing 100101, PR China

\section{H I G H L I G H T S}

- Different species of arsenic absorption by Pteris vittata were inhibited by phenanthrene.

- Phenanthrene absorption by $P$. vittata was reduced by arsenic in the following order: DMA $>\operatorname{As}(\mathrm{V})>\operatorname{As}(\mathrm{III})$.

- Phenanthrene mainly located in the cell membrane or membrane structure.

\section{A R T I C L E I N F O}

\section{Article history:}

Received 8 October 2015

Received in revised form 8 March 2016

Accepted 16 March 2016

Available online 26 March 2016

Handling Editor: X. Cao

\section{Keywords:}

Arsenic

Speciation

Polycyclic aromatic hydrocarbon

Transport

Hyperaccumulator

\begin{abstract}
A B S T R A C T
The interaction between arsenic (As) and phenanthrene (PHE) in Pteris vittata L. was investigated in this study. The migration and occurrence of PHE in P. vittata were determined by two-photon laser scanning confocal microscopy. Data indicated that PHE supplementation lowers the As concentration in P. vittata, decreasing As levels by $16.8-39.9 \%$ in the pinnae, $30.0-49.0 \%$ in the rachis, and $45-51.5 \%$ in the roots, respectively. Different arsenic species inhibited $P$. vittata PHE absorption. The most significant effect was observed using dimethylarsenic acid (DMA), which decreased PHE accumulation by $20.73 \%$. With the exception of elevated $\mathrm{As}(\mathrm{V})$ concentrations in $\mathrm{As}(\mathrm{III})$-treated plants, PHE treatment significantly reduced inorganic As concentrations in P. vittata. However, PHE elevated root DMA concentrations by 9\%. According to in situ visualization, PHE is primarily found in the upper and lower epidermis and stomatal cells, particularly the stomata guard cells.
\end{abstract}

() 2016 Elsevier Ltd. All rights reserved.

\section{Introduction}

The hyperaccumulator, Pteris vittata L., which can absorb and accumulate high-arsenic (As) levels, is used to treat As-polluted soil or water (Sun et al., 2011). As absorbed by P. vittata roots is transported aboveground via the xylem and stored in the fronds. The distribution of As varies in P. vittata generally following the order: pinnae $>$ rachis $>$ roots (Srivastava et al., 2010). The maximum As concentration accumulated in $P$. vittata pinnae can reach $22,630 \mathrm{mg} / \mathrm{kg}$. Interestingly, $93 \%$ of the As was found in the aboveground parts of the plant, which accounts for $2.3 \%$ of the plant dry weight. Furthermore, the As concentration in the

\footnotetext{
* Corresponding author. Institute of Geographical Sciences and Natural Resources Research, Chinese Academy of Sciences (CAS), 11A, Datun Road, Chaoyang District, Beijing 100101, PR China.

E-mail address: Liaoxy@igsnrr.ac.cn (X. Liao).
}

aboveground portions can be up to 25 -fold higher than in the roots (Ma et al., 2001; Tu and Ma, 2002).

Arsenate $[\mathrm{As}(\mathrm{V})]$ is transported to the aboveground portions of $P$. vittata via the vascular bundles, and can undergo biochemical reduction within the plant, primarily being transformed to trivalent As $[\mathrm{As}(\mathrm{III})]$, which is stored in the fronds (Pickering et al., 2006; Hokura et al., 2006). Additionally, other arsenic species, including As(III)-O and As(III)-S compounds, are found in P. vittata (Webb et al., 2003). Energy dispersive X-ray (EDXA) revealed that the As concentration in $P$. vittata pinnae decreased from base to apex, with significantly lower levels in the vein than in the pinna. As was primarily distributed in the vacuoles of the epidermal cells on the upper and lower sides of the pinnae (Lombi et al., 2002). Similarly, Yang et al. (2009) found that $91 \%$ of As was present in the vacuoles, as revealed by subcellular classification. Thus, As reduction and vacuole uptake are important pathways for As detoxification by $P$. vittata, and the major mechanism of As hyperaccumulation. 
As in the environment often coexists with polycyclic aromatic hydrocarbons (PAHs), such as phenanthrene (PHE), which are carcinogenic organic pollutants that degrade slowly. Combined $\mathrm{PAH}$ and As pollution has been found in industrial sites, including coke plants, smelters, and coal mines. As-PAH production exceeded the standard rate by $40.6 \%$ in a smelting industrial site and $68.8 \%$ at a coal mining site in Chenzhou, Hunan Province, China (Zhu et al., 2012). Our previous study revealed that $P$. vittata is capable of absorbing both As and PAHs, which can be used to treat soil with combined As and PAH pollution. In a field investigation conducted at an industrial site in Chenzhou, $P$. vittata was shown to tolerate high As and PAHs levels (1276 mg/kg As and $1.48 \mathrm{mg} / \mathrm{kg}$ PHE) (Sun et al., 2014). Further experimental studies revealed that $P$. vittata tolerates As-PHE co-contamination. Moreover, the co-existence of As and PHE significantly affected As speciation in P. vittata and altered PHE absorption in the roots by significantly elevating PHE root concentrations in the plants (Sun et al., 2011).

The absorption, transport, and storage of As in $P$. vittata have been well-studied (Xie et al., 2009). However, the transportation and localization of PHE in P. vittata remains unclear. In this study, the interaction between different arsenic species and PHE in $P$. vittata was evaluated. The transport and storage patterns of PHE were observed using two-photon laser scanning confocal microscopy (TPLSCM) to better understand the biochemical behaviors and interaction mechanisms of As and PHE in P. vittata.

\section{Materials and methods}

\subsection{Experiment setup}

The spores of $P$. vittata were collected from Chenzhou, Hunan Province, China and evenly spread on a seed tray loaded with medium (flower cultivation soil:vermiculite $=1: 1$ ). The medium was kept moist by watering and covering with a film, and placed in a greenhouse for cultivation. The indoor conditions were: daytime temperature, $25{ }^{\circ} \mathrm{C}$; night temperature, $20^{\circ} \mathrm{C}$; and humidity, $65 \%$. When the spores germinated and developed several young pinnae, the seedlings were isolated and transplanted into 1/5-strength Hoagland solution $(\mathrm{pH}=6.0)$. Healthy and uniform $P$. vittata seedlings were selected for experimental use.

Eight treatments were included in the experiment: control check, PHE, arsenite [As(III)], As(III) + PHE, arsenate [As(V)], $\mathrm{As}(\mathrm{V})+\mathrm{PHE}$, dimethylarsenic acid (DMA), and DMA + PHE. There were three replicates for each treatment. For each group, As was prepared at a final concentration of $10 \mathrm{mg} / \mathrm{L}$ and PHE (dissolved in acetone) was prepared at a final concentration of $2 \mathrm{mg} / \mathrm{L}$ in nutrient solution. Arsenate was added in the form of $\mathrm{Na}_{2} \mathrm{HAsO}_{4} \cdot 7 \mathrm{H}_{2} \mathrm{O}$, arsenite was added in the form of $\mathrm{NaAsO}_{2}$. The nutrient solution was changed every $3 \mathrm{~d}$, and the plants were harvested after $12 \mathrm{~d}$. The harvested plants were washed with clean water and air-dried. The pinnae, rachis, and roots were then separated to measure the fresh weight. A portion of the plant was deactivated at $105{ }^{\circ} \mathrm{C}$ for $30 \mathrm{~min}$ and oven-dried at $65{ }^{\circ} \mathrm{C}$ to obtain the dry weight and determine the total As. The rest of the material was freeze-dried for $24 \mathrm{~h}$, fragmented in an ice bath, and maintained at $-80{ }^{\circ} \mathrm{C}$ to determine the As speciation and PHE concentration.

\subsection{Total arsenic and arsenic speciation analysis}

The oven-dried plant samples were digested with $\mathrm{HNO}_{3}-\mathrm{HClO}_{4}$ (US EPA 3050), and then diluted to a constant volume. Total As was determined using an atomic fluorescence spectrometer (AFS-9130). The national standard (GBW-07603) was used as a reference for analytical quality control.

The plant samples were subjected to ultrasonic extraction with methanol and water $(\mathrm{v} / \mathrm{v}, 1: 1)$. The extract was diluted to a constant volume after rotary evaporation of the methanol. Arsenic speciation were analyzed by liquid chromatography coupled with atomic fluorescence spectroscopy (AFS-LC-9130) (Sun et al., 2011).

\subsection{Phenanthrene analysis}

The plant samples underwent 3 rounds of ultrasound extraction with a mixed solution of acetone and methylene chloride $(\mathrm{v} / \mathrm{v}, 1: 1)$. The upper layer of the extract was concentrated by rotary evaporation to $0.5 \mathrm{~mL}$, and then transferred to a silica gel column for purification. The column was eluted with a mixture of $n$-hexane and methylene chloride. The eluted solution was collected and concentrated by rotary evaporation to $1 \mathrm{~mL}$, followed by the addition of $7-8 \mathrm{~mL} n$-hexane. The solution was concentrated by rotary evaporation to $0.5 \mathrm{~mL}$, mixed with an internal standard, and adjusted to a constant volume of $1 \mathrm{~mL}$. PHE was determined using gas chromatography-mass spectrometry (Agilent6890, USA) $(n=4$, RSD < 9.67). The recovery rate was $96-105 \%$.

\subsection{Detection of PHE fluorescent signal in fresh samples}

The plant samples were washed with distilled water and prepared as live plant sections. The specimens were mounted with neutral gum and observed using TPLSCM (Carl Zeiss LSM 780) equipped with an objective lens (W plan-Apochromat $20 \times / 1.0$ DIC [UV] VIS-IR M27 $75 \mathrm{~mm}$ ). The laser wavelength was set to $710 \mathrm{~nm}$, the emission wavelength was $740 \mathrm{~nm}$, and the detection wavelength was $371-495 \mathrm{~nm}$. Microscopic photographs were analyzed using ZEN 2012 (blue edition) imaging software. The PHE fluorescent signal was blue, and the fluorescent signal of the plant was green.

\subsection{Statistical analysis}

Data were analyzed using SPSS 21.0 (SPSS Inc., Chicago, IL, USA). One-way analysis of variance was used to compare the effects of As on PHE concentration in plant and growth media. Multiple comparisons were made by the least significant difference (LSD) test, and P-values less than 0.05 were considered significant. Two-way analysis of variance was used to compare the interaction of arsenic and PHE. Plots were made using Origin 8.0 and ChemBioOffice.

\section{Results}

\subsection{Concentration of As and PHE in P. vittata}

PHE treatment significantly altered the total As concentration in the pinnae, rachis, and roots of $P$. vittata (Table 1 ). Compared to As treatment alone, the As(III) + PHE, As(V) + PHE, and DMA + PHE treatments decreased pinnae As concentrations by $16.8 \%, 39.9 \%$, and $38.7 \%$, respectively. Furthermore, compared to As treatment alone, PHE significantly inhibited As concentrations in the rachis and roots by $30-49.0 \%$ and $45-51.5 \%$, respectively.

Different arsenic species exhibited a significant effect on PHE absorption by $P$. vittata. Compared to PHE treatment, DMA reduced pinnae PHE concentrations, whereas $\mathrm{As}(\mathrm{III})$ or $\mathrm{As}(\mathrm{V})$ treatment had minor effects. Treatment with different arsenic species decreased PHE concentrations in the roots and rachis of $P$. vittata.

Compared with As treatment alone, PHE decreased 50\% As accumulation of pinnae (Fig. 1). The corresponding rachis and root As decreased by $68.9-117.2$ and $51.2-149.4 \mu \mathrm{g} /$ plant, respectively. PHE-induced inhibition of As accumulation varied between different arsenic species. As $(\mathrm{V})$ showed the greatest decrease in As 
Table 1

Arsenic and PHE concentrations in P. vittata.

\begin{tabular}{|c|c|c|c|c|c|c|}
\hline & \multicolumn{2}{|l|}{ Pinnae } & \multicolumn{2}{|l|}{ Rachis } & \multicolumn{2}{|l|}{ Root } \\
\hline & As (mg/kg DW) & PHE $(\mu \mathrm{g} / \mathrm{kg}$ DW) & As (mg/kg DW) & PHE $(\mu \mathrm{g} / \mathrm{kg}$ DW) & As (mg/kg DW) & PHE $(\mu \mathrm{g} / \mathrm{kg}$ DW $)$ \\
\hline CK & $0.033 \pm 0.001 \mathrm{e}^{*}$ & $48.4 \pm 15.9 c$ & $0.023 \pm 0.01 d$ & $77.7 \pm 22.4 c$ & $0.04 \pm 0.01 \mathrm{e}$ & $34.1 \pm 16.1 b$ \\
\hline PHE & $0.03 \pm 0.001 \mathrm{e}$ & $489 \pm 38.4 a b$ & $0.027 \pm 0.01 d$ & $1098 \pm 77.7 a$ & $0.04 \pm 0.01 \mathrm{e}$ & $2351 \pm 150 a$ \\
\hline $\mathrm{As}(\mathrm{III})$ & $970 \pm 17.9 b$ & $74.3 \pm 7.98 c$ & $379 \pm 40.4 b c$ & $76.1 \pm 12.1 c$ & $331 \pm 36.0 b c$ & $63.0 \pm 14.4 b$ \\
\hline $\mathrm{As}(\mathrm{III})+\mathrm{PHE}$ & $807 \pm 35.0 c$ & $525 \pm 71.0 a$ & $267 \pm 30.0 c$ & $1082 \pm 98.1 a$ & $181 \pm 67.2 d$ & $1949 \pm 142 a$ \\
\hline $\mathrm{As}(\mathrm{V})$ & $1141 \pm 52.4 a$ & $50.5 \pm 9.11 c$ & $593 \pm 115 a$ & $55.5 \pm 16.7 c$ & $404 \pm 35.1 a$ & $53.8 \pm 15.4 b$ \\
\hline $\mathrm{As}(\mathrm{V})+\mathrm{PHE}$ & $685 \pm 4.63 d$ & $489 \pm 34.9 \mathrm{ab}$ & $302 \pm 7.61 c$ & $955 \pm 73.2 \mathrm{ab}$ & $196 \pm 24.6 d$ & $2061 \pm 108 a$ \\
\hline DMA & $1006 \pm 81.8 b$ & $55.3 \pm 13.8 c$ & $556 \pm 29.4 a$ & $45.9 \pm 10.7 c$ & $283 \pm 133 c$ & $51.9 \pm 6.45 b$ \\
\hline $\begin{array}{l}\mathrm{DMA}+\mathrm{PHE} \\
\text { Significance test }\end{array}$ & $616 \pm 72.7 d$ & $429 \pm 30.1 b$ & $370 \pm 43.7 b c$ & $838 \pm 69.2 b$ & $149 \pm 35.9 d$ & $2100 \pm 135 a$ \\
\hline PHE & $\begin{array}{l}F=187 \\
P<0.0001\end{array}$ & $\begin{array}{l}F=432 \\
P<0.0001\end{array}$ & $\begin{array}{l}F=56.0 \\
P<0.0001\end{array}$ & $\begin{array}{l}F=507 \\
P<0.0001\end{array}$ & $\begin{array}{l}F=27.2 \\
P<0.0001\end{array}$ & $\begin{array}{l}F=361 \\
P<0.0001\end{array}$ \\
\hline As speciation & $\begin{array}{l}F=564 \\
P<0.0001\end{array}$ & $\begin{array}{l}F=1.32 \\
P<0.303\end{array}$ & $\begin{array}{l}F=120 \\
P<0.0001\end{array}$ & $\begin{array}{l}F=2.77 \\
P=0.0760\end{array}$ & $\begin{array}{l}F=31.9 \\
P<0.0001\end{array}$ & $\begin{array}{l}F=0.525 \\
P=0.671\end{array}$ \\
\hline PHE $\times$ As speciation & $\begin{array}{l}F=32.4 \\
P<0.0001\end{array}$ & $\begin{array}{l}F=0.737 \\
P<0.545\end{array}$ & $\begin{array}{l}F=9.69 \\
P=0.0007\end{array}$ & $\begin{array}{l}F=1.66 \\
P=0.215\end{array}$ & $\begin{array}{l}F=3.49 \\
P=0.041\end{array}$ & $\begin{array}{l}F=0.698 \\
P=0.567\end{array}$ \\
\hline
\end{tabular}

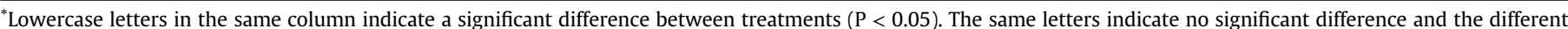
letters indicate a significant difference.

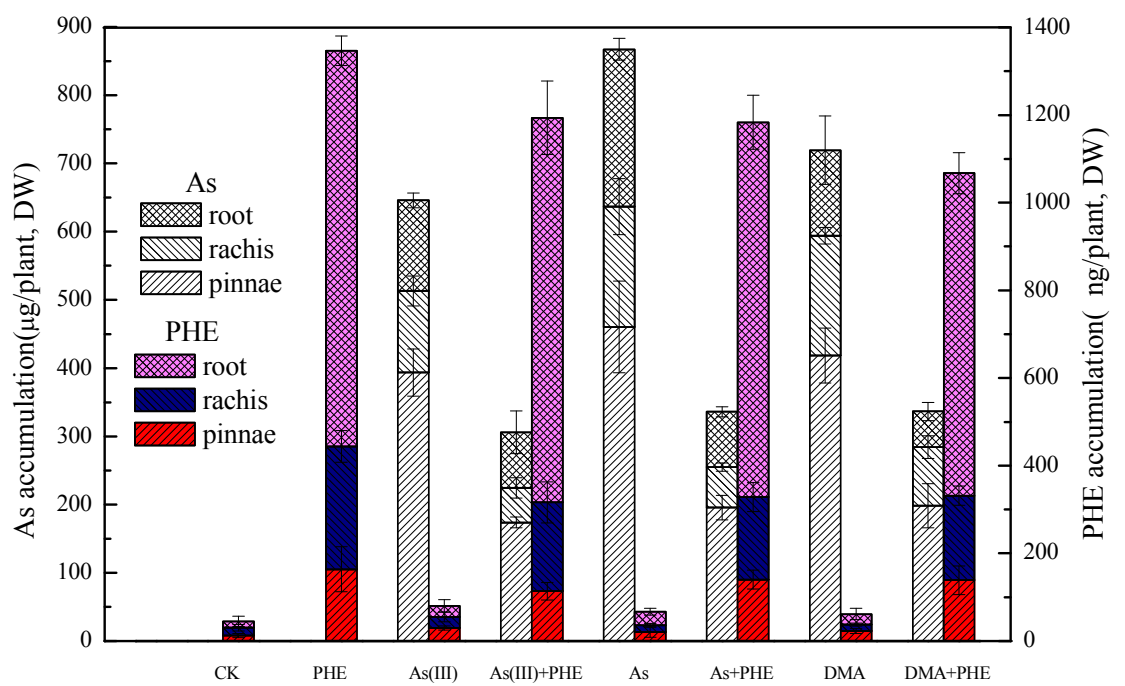

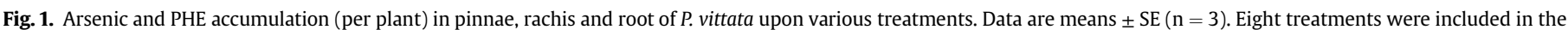
experiment: control check (CK), PHE, arsenite [As(III)], As(III) + PHE, arsenate [As(V)], As(V) + PHE, dimethylarsenic acid (DMA), and DMA + PHE.

accumulation, followed by DMA, whereas As(III) caused a relatively small decrease.

Among the different arsenic species, DMA significantly inhibited PHE accumulation in P. vittata, decreasing accumulation by $295 \mathrm{ng} /$ plant. As(III) and As(V) also inhibited PHE accumulation by 147 and $165 \mathrm{ng} /$ plant, respectively.

\subsection{As speciation in $P$. vittata}

Compared with As treatment alone, PHE significantly decreased pinnae As(III) concentrations. There were also substantial decreases in $\mathrm{As}(\mathrm{III})$ concentrations after $\mathrm{As}(\mathrm{V})$ and DMA treatments $(40.15 \%$ and 56.53\%, respectively), whereas the proportion of As(III) among total As was increased. In contrast, following As(III) treatment, $\mathrm{As}$ (III) concentrations were decreased aboveground, whereas the proportion of $\mathrm{As}(\mathrm{III})$ among total As decreased. This is probably because $\mathrm{As}(\mathrm{V})$ concentrations were greatly decreased by the former two treatments, but slightly increased by the latter. Compared with As treatment alone, PHE and DMA treatments decreased $\mathrm{As}(\mathrm{V})$ concentrations by $56.51 \%$ and $78.83 \%$, respectively. DMA was only detected in the pinnae of plants after DMA treatment. Following
PHE treatment, the proportion of DMA increased by $2.5 \%$, while its concentration decreased by $30.94 \mathrm{mg} / \mathrm{kg}$ dry weight (DW).

In the rachis, PHE had little effect on As speciation following As(III) treatment. However, PHE inhibited the absorption and transformation of different arsenic species following $\mathrm{As}(\mathrm{V})$ and DMA treatments. PHE promoted root absorption of DMA, resulting in an elevation of DMA proportion (9\%) and concentration $(4.3 \mathrm{mg} /$ $\mathrm{kg}$ DW). However, PHE inhibited root absorption of inorganic As (Fig. 2-root).

\subsection{Microscopic distribution of PHE in P. vittata}

PHE signals were observed in different parts of $P$. vittata by TPLSCM (Fig. 3). Following PHE treatment alone, PHE signal was observed in the roots, primarily near the cell wall and in the cytoplasm (Fig. 3A-root). PHE was evenly distributed in the cytoplasm, with individual storage sites in the cells. The intensity of PHE signals in the roots descended as follows: near the cell wall $>$ individual storage sites in the cytoplasm $>$ cytoplasm. In the rachis, PHE was primarily distributed in the U-vascular bundle cells, the walls of the outer cells, and the cytoplasm of certain inner cells 

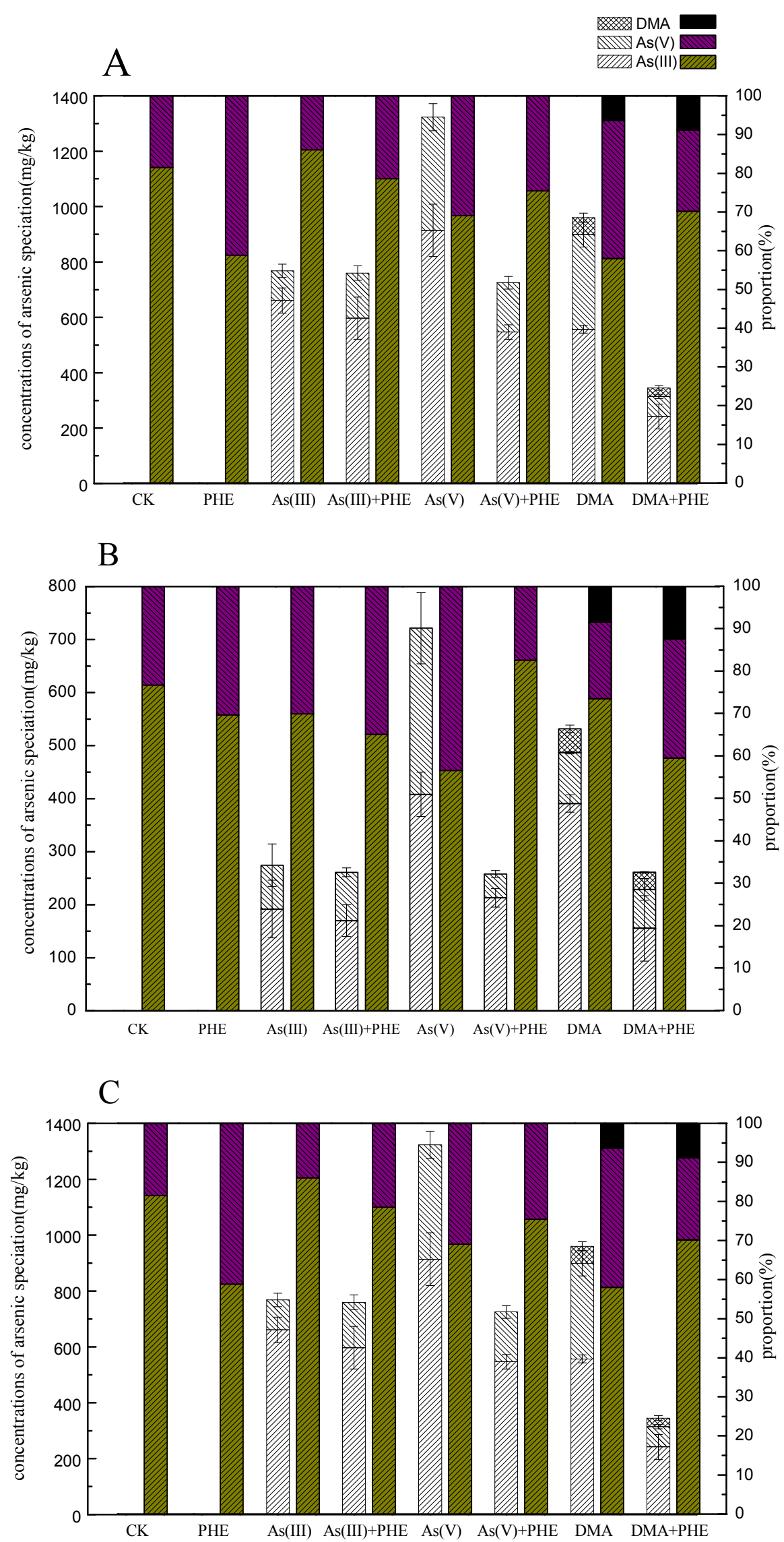

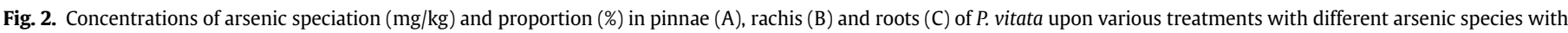
or without PHE. Data are means \pm SE $(n=3)$. 


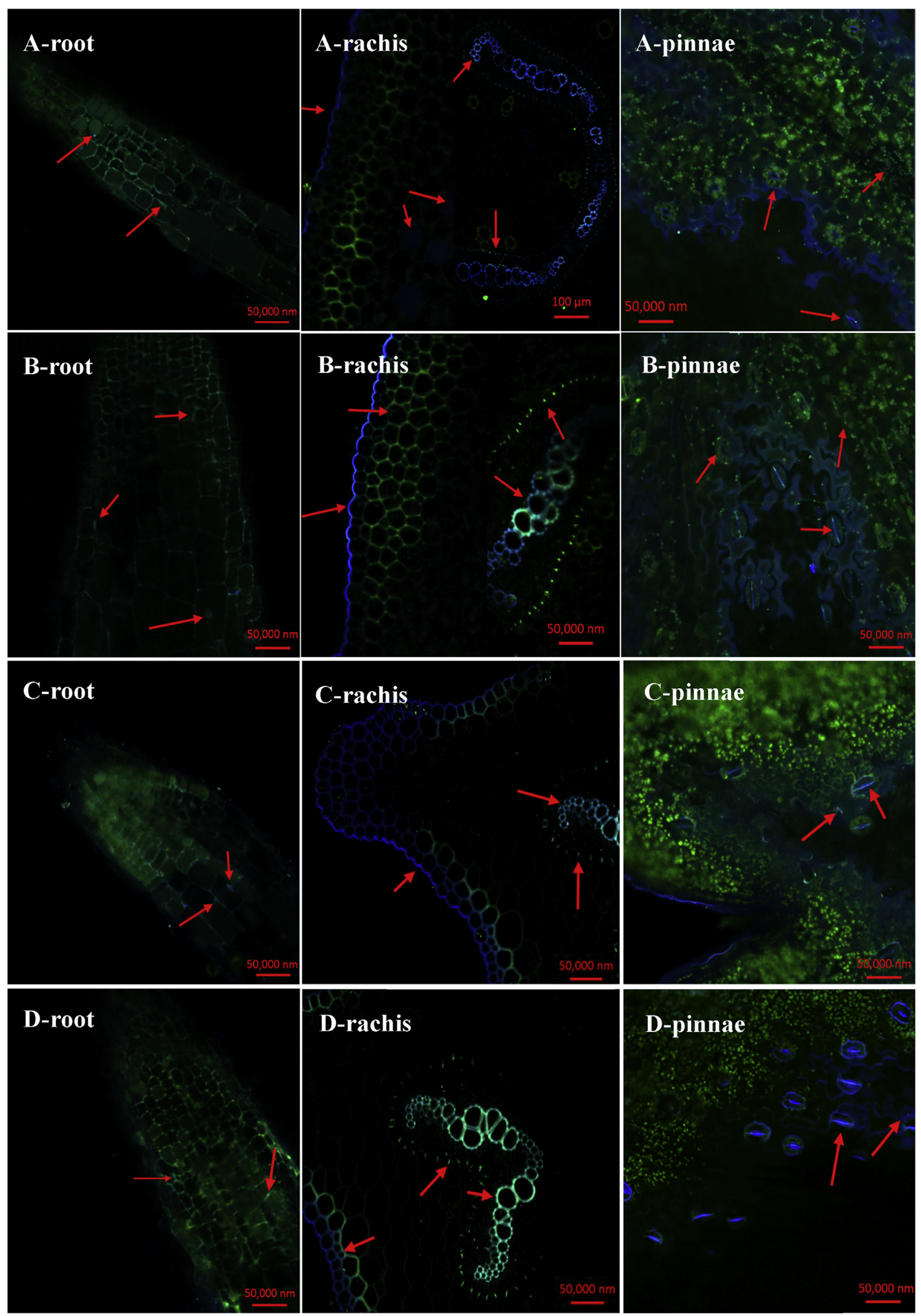

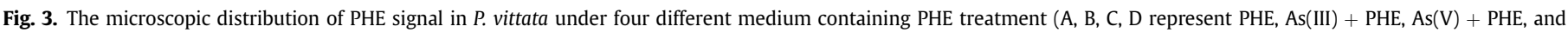

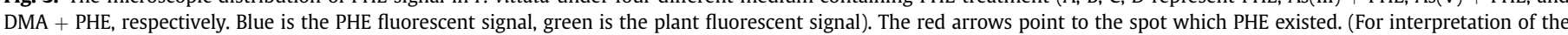
references to colour in this figure legend, the reader is referred to the web version of this article.) 
(Fig. 3A-rachis). The intensity of PHE signal in the rachis varied, as follows: wall of $U$-vascular bundle cells $>$ wall of outer cells $>$ inner cells. In the pinnae, PHE was observed in the pinnae veins, epidermal cells, and a small number of mesophyll cells (Fig. 3Apinnae). The strongest PHE signal in the pinnae was observed in the epidermal cell walls and guard cells. In the epidermal cell cytoplasm, a strong signal was observed on the surface of some organelles (i.e., organelle membranes). The intensity of the PHE signal was as follows: epidermal cells > pinnae veins > mesophyll cells (palisade and spongy tissues).

Different arsenic species did not alter the absorption or localization of PHE, however, they altered the intensity of the PHE signal. After treatment with different arsenic species, PHE signal in the cytoplasm of the root cells was significantly weakened. Following As(V) or DMA treatment, PHE signal was weakened in the outer cell membrane of the rachis. Additionally, the signal intensity of PHE was relatively lower in U-vascular bundles after treatment with different arsenic species.

\section{Discussion}

\subsection{Study on the absorption and translocation of PHE in P. vittata}

In this study, the absorption and transport pathway of PHE in $P$. vittata was speculated in Fig. 4 based on the in situ visualization by TPLSCM. PHE absorbed by root epidermal cells, and then transported to the aboveground portions of the plant through plant apoplast or symplast. The majority of PHE is transported to the fronds through U-vascular bundles in the rachis, while a small portion is transported upward through rachis epidermis cells. PHE is transported to the mesophyll, epidermis, and stomatal guard cells in the fronds through the pinnae veins (Fig. 4).

With the TPLCSM, the absorption and transport of PHE in the roots were observed in Fig. 3. After being cultured in contaminated solutions, PAHs can also be absorbed through the roots and transported to the aboveground parts of the stems and leaves in various plant species, such as Oryza sativa L. (Jiao et al., 2007), Lolium multiflorum L. (Gao et al., 2010) and Helianthus annus L. (Sneath et al., 2013). Transpiration drives the absorption and transport of PAHs from the underground part to the aboveground part (Tao et al., 2006; Mattina et al., 2003; Gao and Zhu, 2004; Wu et al., 2009). For instance, Wang et al. (2012) proposed that PAHs are absorbed in the root epidermis before entering the pith and lateral roots. They then enter the xylem and phloem of the taproot through transpiration. Moreover, the PAHs in the ambient air could deposit to the surface cuticular wax of the leaves (Howsam et al., 2000, 2001).

\subsection{Study on the localization of PHE in P. vittata}

The localization of PAHs in plants are associated with its biochemical behaviors, as well as the structure and function of plant cells. PAHs have a relatively low solubility in water and low Henry's law constants, but are highly lipophilic and have high octanol-water partition coefficients $\left(\mathrm{K}_{\mathrm{ow}}\right)$, while the phospholipid bilayer of the cell membrane is externally hydrophilic and internally lipophilic. The unique characteristics of the phospholipid bilayer cause internal aggregation of PAHs inside the membrane structure (Kang et al., 2010; Haritash and Kaushik, 2009). The phospholipid layer can create a hydrophobic region for accumulation of hydrophobic compounds within the cell membrane. Studies have demonstrated that hexane, paraffins, and PAHs enter the membrane via vesicles (Sikkema et al., 1994; White et al., 1981). Kang et al. (2010) investigated the subcellular distribution of pyrene and PHE in the perennial, ryegrass (Lolium perenne $\mathrm{L}$.), and found that the compounds first

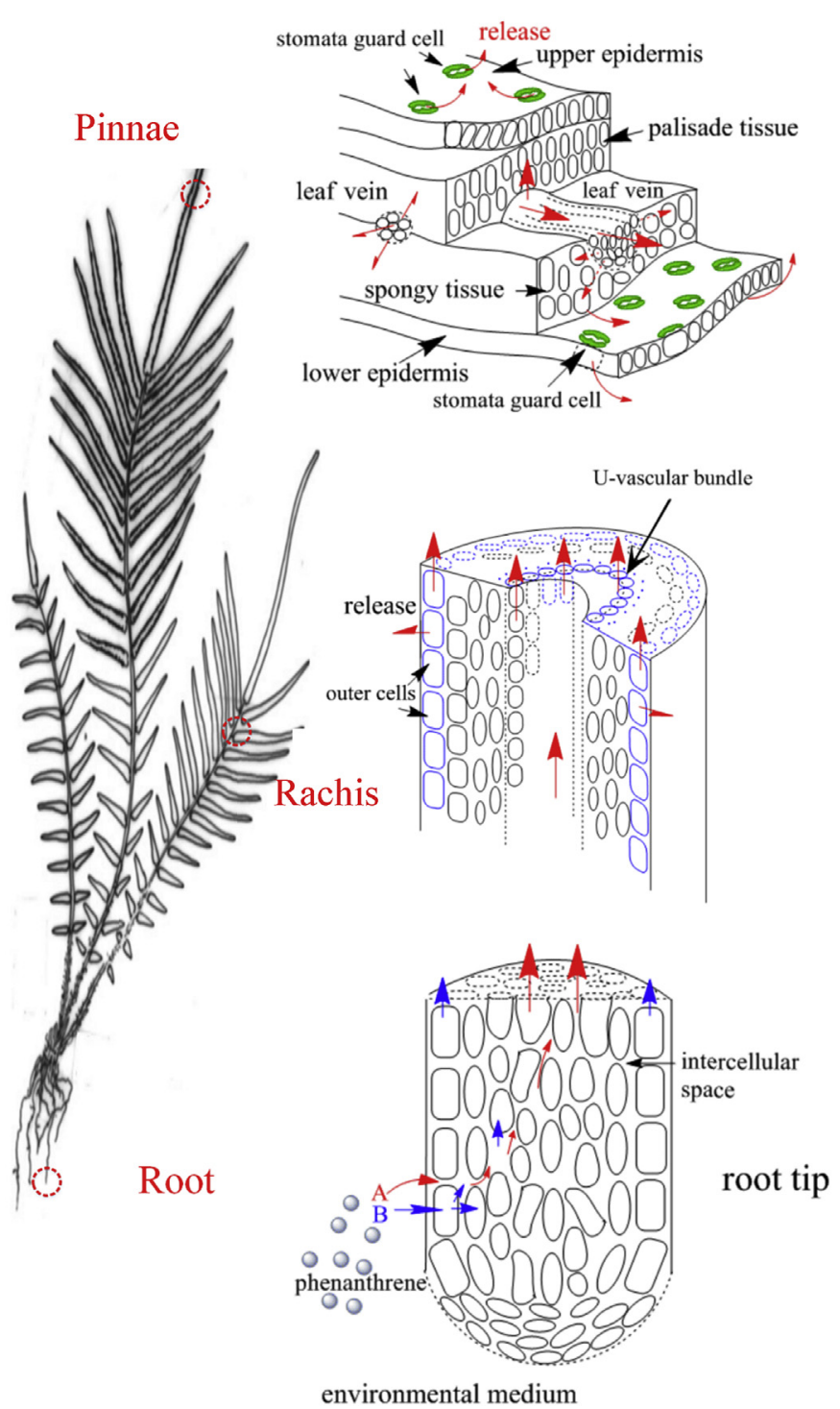

Fig. 4. The simulated pathway diagram of PHE absorption, migration, transportation, and release in P. vittata (Red, blue arrow on behalf of the different way of that process). (For interpretation of the references to colour in this figure legend, the reader is referred to the web version of this article.)

adsorb to the cell wall of the roots, then enter the organelles within the cell via the cell membrane. Ren et al. (2010) compared the transmembrane transport of four typical lipophilic organic compounds, and proposed that PAHs in the extracellular medium enter the cytoplasm in a steady flow through the partition-inverse releasebinding mechanism. Keyte et al. (2009) indicated that PHE was primarily concentrated in the cytoplasm and vacuoles in spinach (Spinacia oleracea), while in the cell membrane and adjacent cells in mosses (Hypnum cupressiforme). In P. vittata, PHE is found in the cell membrane or cytoplasm in different parts of the plant. In the pinnae, PHE is primarily stored in the upper and lower epidermal cells, and the stomatal guard cells of the fronds. The retention of PAHs in the pinnae surface cuticular wax and the cuticle may facilitate the photodegradation and volatilization of the compounds (Wild et al., 2005). Presumably, PHE is exchanged to the external environment or photodegraded in stomatal guard cells, which contain large amounts of PHE, to reduce PHE-induced damage to the plants.

Interestingly, the concentration or signal intensity of PHE in $P$. vittata was influenced by different arsenic species, while the 
migration pathways and storage sites of PHE in the plant had minor effects (Fig. 3). We speculated that PHE and As was regulated by different transporter in P. vittata and PHE was stored in cell membrane owing to its biochemical behaviors (e.g. high $\mathrm{K}_{\mathrm{ow}}$ ). Whether this is the reason for the appearance which showed in Fig. 3 should be explored in future research.

\subsection{Effect of PHE on As migration and transformation in P. vittata}

PHE inhibited As absorption in the roots, rachis and pinnae of $P$. vittata. Additionally, the concentrations of inorganic and organic arsenic species decreased by PHE treatment, with the exception of $\mathrm{As}(\mathrm{V})$ in aboveground portion of the plant and DMA in the root after As(III) and DMA treatment (Table 1). It was inferred that PHE inhibits As absorption for two reasons. Firstly, the activity of the arsenic transporter or arsenate reductase affected by PHE, thereby inhibiting the absorption and transformation of As. The $\mathrm{As}(\mathrm{V})$ reductase gene in $P$. vittata has been coded, and other $A s(V)$ reducing proteins or $\mathrm{As}(\mathrm{V})$ reductases, such as TPI and Grx5, were also involved in reduction (Rathinasabapathi et al., 2006; Sundaram et al., 2008). PHE may affect the normal transport and transformation of As by binding to As transport proteins on the cell membrane or As reductase in the cytoplasm, leading to decrease $\mathrm{As}(\mathrm{III})$ and $\mathrm{As}(\mathrm{V})$ concentrations. Secondly, the transport pathway of different arsenic species, particularly inorganic arsenic, was influenced by PHE. The research of Pickering et al. (2006) demonstrated that, $\mathrm{As}(\mathrm{III})$ and $\mathrm{As}(\mathrm{V})$ are transported through the xylem and phloem in the rachis of $P$. vittata, respectively. $A s(V)$ primarily exists as a bundle in the central vein of the pinnae or the center of the rachis, and primarily plays a role in storage and transportation. In contrast, there was weak signal of As(III) in the central vein of the pinnae; in fact, As(III) presents an interlaced distribution. Moreover, Kachenko et al. (2010) showed that As(III) is present in the vascular bundles of the roots. Sixty percent of $\mathrm{As}(\mathrm{V})$ is absorbed and reduced to $\mathrm{As}(\mathrm{III})$ in the roots, meanwhile, all different speciation of As are transported to the aboveground part of the plant through this vascular bundle tissue. In the present study, it was also revealed that PHE is transported into the cells of the rachis and pinnae through the vascular bundle tissue. Different speciation of As share the channel with PHE for upward transport and migration. PHE likely affects the inorganic As transport capacity of vascular bundle cells leading to a reduction in the As accumulation capacity.

\section{Conclusions}

(1) As absorption in the roots, rachis, and pinnae of $P$. vittata were inhibited by PHE. PHE treatment lowered inorganic and organic As concentrations following different arsenic species treatment, with the exception of the elevated concentrations of $\mathrm{As}(\mathrm{V})$ in the aboveground parts after $\mathrm{As}(\mathrm{III})$ treatment and DMA in the roots after DMA treatment.

(2) Different species of As exhibited an inhibitory effect on PHE absorption in P. vittata. DMA had the greatest inhibitory effect, followed by As(V), and finally, As(III).

(3) PHE mainly occurs in the cell membrane or membrane structure (organelle membrane) and cytoplasm. The specific sites include the membrane and cytoplasm of root cells; epidermis cell membranes, U-vascular bundle cells and the cytoplasm of inner cells in the rachis; veins, epidermal cells and stomatal guard cells in the pinnae.

\section{Acknowledgments}

This work was supported by the National Natural Science Foundation of China (Grant No. 41271339). The National High
Technology Research and Development Program of China (863 Program) (No.2012AA06A201).

\section{References}

Gao, Y., Zhu, L., 2004. Plant uptake, accumulation and translocation of PHE and pyrene in soils. Chemosphere 55, 1169-1178.

Gao, Y., Cheng, Z., Ling, W., Huang, J., 2010. Arbuscular mycorrhizal fungal hyphae contribute to the uptake of polycyclic aromatic hydrocarbons by plant roots. Bioresour. Technol. 101, 6895-6901.

Haritash, A.K., Kaushik, C.P., 2009. Biodegradation aspects of polycyclic aromatic hydrocarbons (PAHs): a review. J. Hazard. Mater. 169, 1-15.

Hokura, A., Omuma, R., Terada, Y., Kitajima, N., Abe, T., Saito, H., Yoshida, S., Nakai, I. 2006. Arsenic distribution and speciation in an arsenic hyperaccumulator fern by X-ray spectrometry utilizing a synchrotron radiation source. J. Anal. Atom. Spectrom. 21, 321-328.

Howsam, M. Jones, K.C., Ineson, P., 2000. PAHs associated with the leaves of three deciduous tree species. I-concentrations and profiles. Environ. Pollut. 108, 413-424.

Howsam, M., Jones, K.C., Ineson, P., 2001. PAHs associated with the leaves of three deciduous tree species. II: uptake during a growing season. Chemosphere 44, 155-164.

Jiao, X.C., Xu, F.L., Dawson, R., Chen, S.H., Tao, S., 2007. Adsorption and absorption of polycyclic aromatic hydrocarbons to rice roots. Environ. Pollut. 148, 230-235.

Kachenko, A.G., Grafe, M., Singh, B., Heald, S.M., 2010. Arsenic species in tissues of the hyperaccumulator. Environ. Sci. Technol. 44, 4735-4740.

Kang, F., Chen, D., Gao, Y., Zhang, Y., 2010. Distribution of polycyclic aromatic hydrocarbons in subcellular root tissues of ryegrass (Lolium multiflorum Lam.). BMC Plant Biol. 10, 210.

Keyte, I., Wild, E., Dent, J., Jones, K.C., 2009. Investigating the foliar uptake and within-leaf migration of PHE by moss (Hypnum cupressiforme) using twophoton excitation microscopy with autofluorescence. Environ. Sci. Technol, 43, 5755-5761.

Lombi, E., Zhao, F.J., Fuhrmann, M., Ma, L.Q., McGrath, S.P., 2002. Arsenic distribution and speciation in the fronds of the hyperaccumulator Pteris vittata. New Phytol. 156, 195-203.

Ma, L.Q., Komar, K.M., Tu, C., Zhang, W., Cai, Y., Kennelley, E.D., 2001. A fern that hyperaccumulates arsenic. Nature 409, 579-579.

Mattina, M.I., Lannucci-Berger, W., Musante, C., White, J.C., 2003. Concurrent plant uptake of heavy metals and persistent organic pollutants from soil. Environ. Pollut. 124, 375-378.

Pickering, I.J., Gumaelius, L., Harris, H.H., Prince, R.C., Hirsch, G., Banks, J.A. George, G.N., 2006. Localizing the biochemical transformations of arsenate in a hyperaccumulating fern. Environ. Sci. Technol. 40, 5010-5014.

Rathinasabapathi, B., Wu, S., Sundaram, S., Rivoal, J., Srivastava, M., Ma, L.Q., 2006. Arsenic resistance in Pteris vittata L.: identification of a cytosolic triosephosphate isomerase based on cDNA expression cloning in Escherichia coli. Plant Molecular Biology, 62, 845-857.

Ren, J.R., Zhao, H.P., Song, C., Wang, S.L., Li, L., Xu, Y.T., Gao, H.W., 2010. Comparative transmembrane transports of four typical lipophilic organic chemicals. Bioresour. Technol. 101, 8632-8638.

Sikkema, J., De Bont, J.A., Poolman, B., 1994. Interactions of cyclic hydrocarbons with biological membranes. J. Biol. Chem. 269, 8022-8028.

Sneath, H.E., Hutchings, T.R., de Leij, F.A.A.M., 2013. Assessment of biochar and iron filing amendments for the remediation of a metal, arsenic and PHE cocontaminated spoil. Environ. Pollut. 178, 361-366.

Srivastava, M., Santos, J., Srivastava, P., Ma, L.Q., 2010. Comparison of arsenic accumulation in 18 fern species and four Pteris vittata accessions. Bioresour. Technol. 101, 2691-2699.

Sun, L., Liao, X., Yan, X., Zhu, G., Ma, D., 2014. Evaluation of heavy metal and polycyclic aromatic hydrocarbons accumulation in plants from typical industrial sites: potential candidate in phytoremediation for co-contamination. Environ. Sci. Pollut. Res. 21, 12494-12504.

Sun, L., Yan, X., Liao, X., Wen, Y., Chong, Z., Liang, T., 2011. Interactions of arsenic and PHE on their uptake and antioxidative response in Pteris vittata L. Environ. Pollut. 159, 3398-3405.

Sundaram, S., Rathinasabapathi, B., Ma, L.Q., Rosen, B.P., 2008. An arsenate-activated glutaredoxin from the arsenic hyperaccumulator fern Pteris vittata L. regulates intracellular arsenite. J. Biol. Chem. 283, 6095-6101.

Tao, S., Jiao, X.C., Chen, S.H., Liu, W.X., Coveney Jr., R.M., Zhu, L.Z., Luo, Y.M., 2006. Accumulation and distribution of polycyclic aromatic hydrocarbons in rice (Oryza sativa). Environ. Pollut. 140, 406-415.

Tu, C., Ma, L.Q., 2002. Effects of arsenic concentrations and forms on arsenic uptake by the hyperaccumulator ladder brake. J. Environ. Qual. 31, 641-647.

Wang, P., Wu, T., Zhang, Y., 2012. Monitoring and visualizing of PAHs into mangrove plant by two-photon laser confocal scanning microscopy. Mar. Pollut. Bull. 64, $1654-1658$.

Webb, S.M., Gaillard, J.F., Ma, L.Q., Tu, C., 2003. XAS speciation of arsenic in a hyperaccumulating fern. Environ. Sci. Technol. 37, 754-760.

White, S.H., King, G.I., Cain, J.E., 1981. Location of hexane in lipid bilayers determined by neutron diffraction. Nature 290, 161-163.

Wild, E., Dent, J., Thomas, G.O., Jones, K.C., 2005. Real-time visualization and quantification of PAH photodegradation on and within plant leaves. Environ. 
Sci. Technol. 39, 268-273.

Wu, N., Huang, H., Zhang, S., Zhu, Y.G., Christie, P., Zhang, Y., 2009. PHE uptake by Medicago sativa $L$. under the influence of an arbuscular mycorrhizal fungus. Environ. Pollut. 157, 1613-1618.

Xie, Q.E., Yan, X.L., Liao, X.Y., Li, X., 2009. The arsenic hyperaccumulator fern Pteris vittata L. Environ. Sci. Technol. 43, 8488-8495.
Yang, X., Chen, H., Dai, X., Xu, W., He, Z., Ma, M., 2009. Evidence of vacuolar compartmentalization of arsenic in the hyperaccumulator Pteris vittata. Chin. Sci. Bull. 54, 4229-4233.

Zhu, G.H., Sun, L., Liao, X.Y., Yan, X.L., Zhou, L.X., 2012. Combined pollution heavy metals and PAHs and its risk assessment in industrial sites of Chenzhou city. Geogr. Res. 31, 831-839 (In Chinese). 